Nghiem, L.D. ; Schäfer, A.I. (2002) Adsorption and Transport of Trace Contaminant Estrone in NF/RO Membranes, Environmental Engineering Science (invited special issue paper) $19,6,441-451$. doi:10.1089/109287502320963427.

\section{ADSORPTION AND TRANSPORT OF TRACE CONTAMINANT ESTRONE IN NF/RO MEMBRANES}

L.D. Nghiem and A.I. Schäfer*

Centre for Water \& Waste Technology School of Civil \& Environmental Engineering

The University of New South Wales, Sydney NSW 2052 Australia
Abstract

Despite of their low concentration, the impact of steroid estrogens such as estrone, $17 \beta$ estradiol and ethinylestradiol are often more serious than other synthetic endocrinedisrupting chemicals (EDCs) since their endocrine-disrupting potency is much higher While their existence in waterways is of increasing concern, nanofiltration (NF) and reverse osmosis (RO) are likely to play an important role in removal of these compounds. reverse osmosis (RO) are likely to play an important role in removal of these compounds.
This paper describes the mechanisms involved in the retention of estrogen estrone using NF and RO.

$\mathrm{NF} / \mathrm{RO}$ membranes may adsorb trace contaminant estrone, which may result in an initially high retention. If the pore size of the membranes is larger than the estrone molecules, breakthrough can be observed when the membrane adsorptive sites are saturated. Although the can be observed when Although there is negligible effect of ionic strength on estrone adsorption by the membrane, it is strongly influenced by $\mathrm{pH}$ near the pKa value of estrone (10.4). While static adsorption experiments give a linear adsorption isotherm, higher estrone adsorption in the filtration process with a large pore size membrane (TFC-SR2) suggests that adsorption can also occur inside the membrane active layer.

Depending on the pore size to molecule size ratio, the transport of trace organics across the membrane active layer can be described as diffusive and/or convective. A modified diffusion model is proposed to assess the degree of diffusive to convective transport of trace contaminant estrone across the membrane.

\section{Keywords}

Endocrine disrupters, hormones, nanofiltration, reverse osmosis, adsorption, water and wastewater treatment. 
Nghiem, L.D. ; Schäfer, A.I. (2002) Adsorption and Transport of Trace Contaminant Estrone in NF/RO Membranes, Environmental Engineering Science (invited special issue paper) 19, 6, 441-451.

\section{INTRODUCTION}

The effects of endocrine-disrupting chemicals (EDCs) on both humans and the environment are of increasing concern. The European Commission (1996) has defined an EDC as "an exogenous substance that causes adverse health effects in an intact its progeny, consequent to endocrine function". Over the last few years, intensive attempts have been made to study a wide variety of effects that has been attributed to EDCs. A multitude of environmental effects already observed include increase vittellogenin levels, which is used as a bio-indicator of femininity in fish, in male and juvenile female fish in and immediately downstream of the sewage effluent discharge points (Jobling et al., 1998; Purdom et al., 1994; Harries et al., 1997) and declining fertility in young alligators due to endocrine modulator DDT (Piva and Martini, 1998). Most recent studies by many researchers have confirmed the impacts of EDCs on trout at the common concentration encountered in sewage effluent (Rodgers-Gray et al., 2001; and Thorpe al., 2001).

Amongst a vast number of EDCs the impacts of steroid estrogens such as estrone, $17 \beta$ estradiol (natural hormones) and 17a-ethinylestradiol (a synthetic hormone, the main component of the contraceptive pill) are prominent as they have far higher endocrinedisrupting potency than most synthetic EDCs. Estrone and $17 \beta$-estradiol are mainly produced in the ovary and during pregnancy in the placenta. They control the development of the secondary female sex characteristics in women and together with the gestagens, control the reproductive process (Turan, 1995). Being excreted by humans, such steroid estrogens are ubiquitous in aquatic environments receiving sewage effluent. They were frequently detected in Canadian and German sewage treatment plants (STP) discharge effluent within the lower $\mathrm{ngL}^{-1}$ range. Estrone concentration of up to $70 \mathrm{ngL}^{-1}$ in STP effluent was also reported (Ternes et al., 1999). The performance of conventional wastewater treatment plants with regards to removal of steroid estrogens varies greatly and, in consequence, concentrations of some steroid estrogens in secondary effluent often remain high enough to harm wildlife such as fish in particular (Johnson and Stumpter, In spite of the magnitude of this problem, research on the removal of EDCs in water and wastewater has been limited to date due to their relatively low concentration and the associated analytical difficulties. This is particularly true for steroid estrogens as only at a few ng/L, 17ß-estradiol may cause distinctive effects on fish (Purdom et al., 1994). The accumulation of synthetic and natural hormones in the environment is largely unknown. Given the seriousness of possible effects (fertility, development, behaviour) the understanding of removal of such contaminants in water and wastewater is of uttmost importance for water and wastewater treatment.

Membrane processes have been widely accepted of being able to comply with more stringent requirements in water and wastewater treatment. Given the potential impacts of EDCs such as estrone and 17 -estradiol, and inadequate and inconsistent performance of conventional wastewater treatment in regard to such compounds, nanofiltration (NF) and reverse osmosis $(\mathrm{RO})$ are likely to play an important role in the removal of EDCs.

Retention of trace organics by NF/RO membranes has been the subject of considerable research (Chian et al., 1975; Baier et al., 1987; Duranceau et al., 1992; Berg et al., 1997; Kiso et al., 2001; Schäfer et al., 2001). Depending on their affinity to the membrane material, retention of trace organics by NF/RO membranes can be governed by a complex fashion according to the chemistry of the solute-membrane interactions. In such circumstances, molecular weight of organic solutes and salt retention of the membranes may be a poor predictor of the retention (Wiesner and Buckley, 1996; Schäfer et al., 2001). It has been reported that NF/RO processes are capable of removing trace organics including a wide range of pesticides, synthetic organic compounds and natural hormones (Chian et al. 1975; Duranceau et al. 1992; Berg et al. 1997; Kiso et al, 2000; Kiso et al., at al. 2001). In our previous work, removal of the trace contaminant estrone and $17 \beta$-estradiol using eight different nanofiltration and reverse osmosis membranes has been studied. It was found that some membranes could adsorb such trace organics and may subsequently give an impression of high retention (Nghiem et al., accepted). Retention behaviour of such trace organics is often explained by the solution diffusion model (Wiesner and Buckley, 1996). According to this model, solute transport across the membrane is a two step process: firstly, the solute is adsorbed or dissolved by the membrane; secondly, it migrates across the membrane by diffusion or convection. Molecular characteristics such as water solubility, hydrogen bonding, acidity and branching can affect both the adsorption and the migration processes (Reinhard et al., 1986). Jones and O'Melia (2000) developed a rate model to investigate the adsorption of macromolecule bovine serum albumin (BSA) and humic acid on UF membranes. This mode also suggests a two stage process which is diffusion of the organics to the proximity of the membranes followed by adsorption on the membrane surface. Being large macromolecules, it is anticipated that BSA and large humic acid molecules are rejected by UF membranes mostly due to size exclusion and adsorption of such compounds can only occur on the membrane surface. On the other hand, steroid estrogens are much smaller; thus, penetration of these compounds into the pores of NF and even some some RO membranes may be possible. Consequently, physico-chemical interactions between the membrane polymer and steroid estrogens are likely to play an important role in governing the adsorption process. While in the study by Jones and O'Melia adsorption of BSA was induced by hydrophobic interaction, steroid estrogens adsorption on NF/RO membranes may be mainly governed by specific interactions such as hydrogen bonding.

This paper investigates the adsorptive behavior of the natural hormone estrone on eight different NF and RO membranes in an attempt to establish a relationship between adsorption, pore size and retention of steroid estrogens. Interaction between estrone and the membrane polymer under various $\mathrm{pH}$ and ionic strength values of the feed solution and their effects on estrone adsorption by the membranes were examined. A modified diffusion model developed by Jones and O'Melia (2000) was adapted to depict the diffusive/convective transport of estrone across the membranes in order to gain further understanding of the estrone retention mechanisms by NF/RO membranes.

\section{Materials and Methods}

\section{Membranes}

Eight commercially available membranes were selected for this study, namely TFC-S, TFC-ULP, TFC-SR1, and TFC-SR2 supplied by Koch Membrane Systems (San Diego, USA) and X-20, ACM-4, TS-80, and XN-40 supplied by Trisep Corporation (Goleta, USA). Membrane types, materials, pure water fluxes at 5 bar and membrane resistances are Membrane types, materials, pure water fluxes at 5 bar and membrane resistances are
summarised in Table 1 . It has been shown in our previous work that all membranes are negatively charged near pH neutral (Schäfer et al., submitted).

\section{Filtration System and Protoco}

Filtration experiments were carried out in a $185 \mathrm{~mL}$ stainless steel stirred cell. Details of the filtration system were described elsewhere (Schäfer et al., 2001). The inner diameter was $56.6 \mathrm{~mm}$ resulting in a membrane surface area of $21.2 \mathrm{~cm}^{2}$. An Amicon magnetic 
Nghiem, L.D. ; Schäfer, A.I. (2002) Adsorption and Transport of Trace Contaminant Estrone in NF/RO Membranes, Environmental Engineering Science (invited special issue paper) $19,6,441-451$.

stirrer was used and the stirrer speed was set at $400 \mathrm{rpm}$ to minimize concentration polarisation effects. Instrument grade air was used to pressurize the stirred cell. The membranes were gently washed using MilliQ water to remove the protective coating and a new membrane was used for each experiment. Three membranes with varying retentions were selected.

Each experiment was conducted in three steps. The membranes were compacted for 1 hour using MilliQ water at 10 bar. Pure water flux was then determined at 5 bar. In the third step, the reservoir was emptied and the cell filled with the test solution. The solution was filtered at 5 bar or 10 bar for Koch (TFC-SR2 and TFC-S) and Trisep (X-20) membranes respectively, to obtain comparable flux values. Unless otherwise stated, six permeate samples of $20 \mathrm{~mL}$ each were collected from the filtration of a feed volume of $185 \mathrm{~mL}$. Feed and concentrate samples were also collected for analysis.

\section{Static Adsorption Experiments}

Adsorption experiments were performed in an automatic incubator shaker (Bioline, Edwards Instrument Company, Australia). A membrane area of $21.2 \mathrm{~cm}^{2}$ was gently washed using MilliQ water as for filtration experiment. Since estrone can approach the membrane from both sides, double the membrane area $\left(42.4 \mathrm{~cm}^{2}\right)$ was used for calculation. The support layer was neglected for adsorption as it cannot form hydrogen calculation. The support layer was neglected for adsorption as it cannot form hydrogen
bonds. The membrane was then cut into small pieces and placed in a conical flask. $50 \mathrm{~mL}$ bonds. The membrane was then cut into small pieces and placed in a conical flask. $50 \mathrm{~mL}$ concentration of estrone was introduced to the flask. The flask was immediately placed into the shaker and $1 \mathrm{~mL}$ of sample was taken for every measurement as the experiment progressed. The flask was covered with nylon film to avoid evaporation and shaken at 100 $\mathrm{rpm}$ to ensure a homogeneous solution. A temperature of $25^{\circ} \mathrm{C}$ was maintained throughout the experiment.

\section{Solution Chemistry and Chemicals}

All chemicals were of analytical grade. Radiolabelled estrone-2,4,6,7- ${ }^{3} \mathrm{H}(\mathrm{N})$ was purchased from Sigma Aldrich (Saint Louis, Missouri, USA). The background electrolyte consisted of $1 \mathrm{mM} \mathrm{NaHCO}_{3}$, and $20 \mathrm{mM} \mathrm{NaCl}$. pH was adjusted using $1 \mathrm{M} \mathrm{HCl}$ or $1 \mathrm{M} \mathrm{NaOH}$.

\section{Natural Hormone Characteristics and Analysis}

Estrone has a very low solubility in water (Merck, 1996) with a molecular weight of 270 gmol $^{-1}$. Diameter of the equivalent sphere of the molecule is estimated to be about $0.8 \mathrm{~nm}$
using the Stokes-Einstein equation. The acid dissociation constant, pKa, of estrone is 10.4 using the Stokes-Einstein equation. The acid dissociation constant, pKa, of estrone is 10.4
(Schäfer et al., submitted). Hydroxyl and carbonyl functional groups of estrone can facilitate the formation of hydrogen bonding between the molecule and the membrane surface. Theoretically, estrone can be either a proton-donor or a proton-acceptor species. Molecular structure of estrone and possible hydrogen bonding formations with the membrane functional groups are shown in Figure 1.

. Feed solution was prepared by spiking estrone into background electrolyte solution to an estrone concentration of $100 \mathrm{ng} / \mathrm{L}$, which presents a typical concentration of natural hormones often encountered in water and wastewater treatment. Estrone was analysed using a Packard Instruments scintillation counter.

Adsorption of estrone by the membranes was determined by mass balance calculation The mass balance equation is defined as:

$$
C_{F} V_{F}=A \Gamma+V_{P} \sum_{1}^{n} C_{p i}+C_{c} V_{c}
$$

where $A$ is the membrane area $\left(\mathrm{cm}^{2}\right) ; \Gamma$ is the amount of estrone adsorbed per surface area $\left(\mathrm{ngcm}^{-2}\right)$ and $\mathrm{n}$ is the number of permeate samples; $C_{F}, C_{P}, C_{C}$ and $V_{F}, V_{P}, V_{C}$ are concentration and volume of feed, permeate and concentrate respectively.

Adsorption was also determined by cutting the membrane into small pieces at the conclusion of each experiment. The membrane was then placed into a scintillation vial to which $5 \mathrm{~mL}$ of acetone was added. The vial was shaken vigorously and left for 1 hour for all estrone to dissolve. $1 \mathrm{~mL}$ of solution was extracted into another vial for air-drying. The residue was redissolved with $1 \mathrm{~mL}$ of MilliQ water and analysed after adding $9 \mathrm{~mL}$ of scintillation liquid. Both methods produced similar results.

\section{RESULTS AND DISCUSSION}

\section{Breakthrough Observations}

In our previous studies, we have shown that estrone can be adsorbed by polyamide membranes, presumably due to hydrogen bonding (Schäfer, et al., submitted; Nghiem et al., accepted). Adsorption and convection will dominate the transport of estrone across the membranes, if their pore sizes are larger than estrone molecule. Due to adsorption, estrone transport is retarded across the membrane layer and consequently estrone retention depends on the adsorption process until the material is saturated. To investigate this relationship between adsorption and the pore size of the membrane, filtration experiments were conducted with a series of fresh feed solutions for TFC-S and X-20 curve is apparent for the TFC-S membrane, of which the pore size is speculated to be in the same order of magnitude as the size of the estrone molecule. Nevertheless, the permeate concentration of TFC-S membrane becomes stable below the feed concentration, which indicates some degree of retention due to a sieving mechanism. A breakthrough curve is not observed for the X-20 membrane. For tight membranes, diffusion controls the rate of trace organic transfer across the membrane and the separation process can be achieved through sieving mechanism.

\section{pH and lonic Strength Effects}

Batch filtration experiments were performed to investigate the effect of solution condition ( $\mathrm{pH}$ and ionic strength) on the adsorption of estrone. A new membrane was used for each $\mathrm{pH}$ and ionic strength concentration. Adsorption in nanograms $\left(10^{-9} \mathrm{~g}\right)$ of estrone per $\mathrm{pH}$ and ionic strength concentration. Adsorption in nanograms $\left(10^{-9} \mathrm{~g}\right)$ of estrone per
membrane surface area $\left(\mathrm{cm}^{2}\right)$, from a $100 \mathrm{ngL}^{-1}$ solution by TFC-SR2, TFC-S and X-20 membrane surface area $\left(\mathrm{cm}^{2}\right)$, from a $100 \mathrm{ngL}^{-1}$ solution by TFC-SR2, TFC-S and X-20
membranes as a function of $\mathrm{pH}$ is shown in Figure 3 . Variation in $\mathrm{pH}$ of the solution can membranes as a function of $\mathrm{pH}$ is shown in Figure 3. Variation in $\mathrm{pH}$ of the solution can result in conformational changes of the estrone molecules and the membrane structure or the electrostatic interaction between estrone and the membrane surface, which will ultimately influence estrone adsorption onto the membrane. A trend of slight reduction in adsorption as $\mathrm{pH}$ increased at $\mathrm{pH}$ below the dissociation constant of estrone $(\mathrm{pKa}=10.4)$ indicates that some degree of hydrophobic adsorption may exist, although the trend is too minor to draw any conclusive statements. For TFC-SR2 and TFC-S membranes, estrone adsorption decreases dramatically as the $\mathrm{pH}$ exceeds the pKa value of estrone, which suggests that site-specific adsorption plays a more importance role in this case. Estrone suggests that site-specific adsorption plays a more importance role in this case. Estrone
adsorption by the X-20 membrane is considerably less than that by the TFC-S and TFC$\mathrm{SR} 2$ membranes. Consequently, a sudden reduction in adsorption when $\mathrm{pH}$ exceeds the pKa value of estrone was not observed with this membrane. As proposed in our earlier work, when dissociated, estrone loses its proton and become a negative species; it is unable to form hydrogen bonds with the membrane functional groups, resulting in a sudden reduction in adsorption (Schäfer et al., submitted). A more gradual reduction in hydrophobic adsorption of bovine serum albumin (BSA) on regenerated cellulose 
Nghiem, L.D. ; Schäfer, A.I. (2002) Adsorption and Transport of Trace Contaminant Estrone in NF/RO Membranes, Environmental Engineering Science (invited special issue paper) $19,6,441-451$.

membranes when $\mathrm{pH}$ exceeds the isoelectric point (IEP) of BSA was observed by other researchers (Jones and O'Melia, 2000).

Figure 4 shows estrone adsorption from a $100 \mathrm{ngL}^{-1}$ feed solution onto a TFC-SR2 membrane as a function of $\mathrm{NaCl}$ concentration at $\mathrm{pH}$ near neutral. The ionic strength, or $\mathrm{NaCl}$ concentration may partially screen electrostatic potentials and polarity. While modification of molecular structure is important for large molecules, the effect with estrone is likely to be minimal. Similarly, the ionic strength may reduce the electrostatic interaction is litwe the molocion between the moth phenomena can influence hydrophobic interactions between estrone molecule and the membrane surface. Although, there is some variation in adsorption as $\mathrm{NaCl}$ concentration varies from 0 to $100 \mathrm{mM}$, no obvious trend can be observed. This further indicates that site-specific interaction dominates the adsorption mechanism.

Retention of estrone by TFC-SR2 as a function of $\mathrm{pH}$ and $\mathrm{NaCl}$ concentration resembled the curve presented in Figure 3 \& Figure 4 (data not shown). High initial estrone retention (above $90 \%$ ) at low $\mathrm{pH}$ and low estrone retention (about 55\%) clearly indicate that retention in this case was mainly governed by adsorption. Drop in adsorption resulted in a milder decline in retention of estrone by TFC-S membrane. Whereas, no decline in retention of estrone by the X-20 membrane was observed when estrone adsorption retention of estrone by the X-20 membrane was observed when estrone adsorption decreased. As the membrane pore size (based on salt retention studies) is in the order
TFC-SR2>TFC-S>X-20, these results show that effect of adsorption on retention of estrone by NF/RO membranes can be pore size dependent. The data is published by Schäfer et al. (submitted).

\section{Adsorption Isotherms}

Estrone adsorption as a function of feed concentration $\left(1,10,100\right.$, and $\left.1000 \mathrm{ng}^{-1}\right)$ on log scale for the TFC-S and TFC-SR2 membranes in stirred cell filtration experiments are presented in Figure 5 . Both membranes show a linear curve with a similar partition coefficient $\mathrm{K}$ of $48 \mathrm{Lm}^{-2}$.

The adsorption isotherms of TFC-SR2 and X-20 membranes are obtained using static The adsorption isotherms of TFC-SR2 and $X-20$ membranes are obtained using static
adsorption experiment (membrane pieces in flasks) and presented Figure 6 . While the adsorption isotherms of the two membranes are also linear, which is common in very dilute system (Do, 2001), partition coefficients are significantly lower, 8.1 and 4.0 for TFC-SR2 and X-20 membranes, respectively.

During the filtration process, hydraulic resistance is overcome by convection since the pore size of TFC-S and TFC-SR2 is similar or larger than estrone molecule. Estrone can penetrate into the (a) presumably due to hydrogen bonding, can occur.

In contrast, diffusion is the only driving force in the static adsorption process. Due to the small pores of the active layer, hydraulic resistance reduces the penetration of estrone and adsorption occurs mainly at the surface. Consequently, a much smaller amount of estrone is adsorbed as can be observed in the static adsorption experiments. The difference in partition coefficient of TFC-SR2 (very loose NF) and X-20 (RO) membrane can be attributed to the fact that the pore size of the X-20 membrane is smaller than the estrone molecule and adsorption can only occur at the surface of the active layer. Although it is possible for the supporting layer to adsorb estrone, results reported here also indicate that the active layer indeed dominates the adsorption process as previously suggested by Chian et al., (1975) and William et al., (1999) for other membranes. The Pore size of the supporting layer is in the order of $100 \mathrm{~nm}$ (William et al., 1999), thus, hydraulic resistance is expected to be negligible and the partition coefficient obtained in filtration and static adsorption experiment would be similar if adsorption to the supporting layer dominates (in static experiments the contaminants can adsorb from both sides of the membranes). This is consistent with the results reported by William and co-workers (1999) who found that the majority of trichlorophenol was adsorbed by the active layer of FT30-BW membrane (polyamide on polysulphone support) and subsequent flux decline was observed as an indication of site specific adsorption. However, flux decline could not be observed in our experiments due to very low concentrations of estrone.

\section{Adsorption \& Desorption Kinetics}

The results from the study of the adsorption kinetics in static flask experiments are shown in Figure 7. After about 200 minutes the adsorption of estrone by the TFC-SR1, TFC-SR2 and $\mathrm{XN}-40$ has attained the plateau value, while this takes significantly longer for the TS80 , ACM- 4 and X-20 membranes. Despite the fact that all membranes are made of the similar polymer, this indicates some difference in physical characteristics of the

similar polym
membranes.

Unlike adsorption kinetics, desorption kinetics of all membranes follow the same pattern and reach equilibrium at 200 minutes. However, considering the adsorption isotherms of the TFC-SR2 and X-20 membranes (see Figure 6), it can be seen in Figure 8 that the desorption process is not complete. This may present an irreversibility factor at this experimental condition, as desorption is lower than what would be expected from the equilibrium established due to the concentration in the bulk after desorption.

\section{Diffusive versus Convective Transport}

In pressure driven membrane filtration processes, the transport of uncharged microorganic compounds, which have high affinity to the membrane material, across the membrane active layer can be convective and/or diffusive, depending on the pore size of the membrane and the MW of the organic. Consequently, one would expect that the degree of diffusive to convective transport may significantly influence the retention of trace organics in NF/RO membrane filtration. A simplified schematic diagram showing the transport of trace organics across NF/RO membrane during filtration process is presented in Figure 9. The schematic descibes an ideal NF membrane as convective while an ideal $\mathrm{RO}$ membrane is diffusive. For a real membrane convention and diffusion co-exist.

To assess the degree of diffusive to convective transport of trace contaminant estrone in NF/RO membranes, a modified diffusion model developed by Jones and O'Melia (2000) $\mathrm{NF} / \mathrm{RO}$ membranes, a modified diffusion model developed by Jones and O'Melia (2000) solution to the one-dimensional diffusion equation was used to describe adsorption at the thin film interface between bulk solution and the membrane surface. Fick's law yield for one-dimensional isothermal diffusion in homogeneous films of a sufficiently large area is:

$$
\frac{\partial C}{\partial t}=\frac{\partial}{\partial x}\left\{D_{(s w)} \frac{\partial C}{\partial x}\right\}
$$

where $C$ is the bulk concentration of the solute, $t$ represents the time and $D_{(s w)}$ is the diffusion coefficient of the solute in water, $\mathrm{x}$ is the distance from the membrane surface.

In order to solve Eq. (2) it can be assumed that the diffusion coefficient of the solute in water is constant and that the concentration of estrone at the solid/liquid boundary remains zero during the diffusion process (Jones and O'Melia, 2000). Eq. (2) then becomes:

$$
\frac{\partial C}{\partial t}=D_{(s w)} \frac{\partial^{2} C}{\partial x^{2}}
$$

The following initial and boundary conditions apply: initial condition $\quad \mathrm{C}(\mathrm{x}, 0)=\mathrm{C}_{0}(\mathrm{x}>0)$ $\begin{array}{ll}\text { boundary conditions } & \mathrm{C}(\mathrm{x}, \mathrm{t})=\mathrm{C}_{0}(\mathrm{x}>0) \\ & \mathrm{C}(\mathrm{t})=0 \text { and } \mathrm{C}(\infty, \mathrm{t})=\mathrm{C}_{0}\end{array}$

where $C_{0}$ is the initial bulk concentration of the solute. With the above conditions Eq. (3) can be solved to yield: 
Nghiem, L.D. ; Schäfer, A.I. (2002) Adsorption and Transport of Trace Contaminant Estrone in NF/RO Membranes, Environmental Engineering Science (invited special issue paper) $19,6,441-451$.

$$
C=C_{0} \operatorname{erf} \frac{x}{\left(4 D_{(s w)} t\right)^{1 / 2}}
$$

The solute flux to the membrane is:

$$
J=\left.D \frac{\partial C}{\partial t}\right|_{x=0}=C_{0}\left(\frac{D_{(s w)}}{\pi t}\right)^{1 / 2}
$$

As the adsorption process proceeds, both the number of sites available for adsorption and the concentration of estrone in the bulk solution decrease. More specifically, the number of adsorptive sites and bulk concentration for which Eq. (5) is valid decrease as adsorption adsorptive sites and bulk concentration for which Eq. (5) is valid decrease as adsorption
progresses. Consequently, the term $\left[1-\Gamma_{(\mathrm{t})} / \Gamma_{\mathrm{e}}\right]$ must be introduced to account for this decrease (Jones and O'Melia, 2000). $\Gamma_{\mathrm{e}}$ is the amount of trace organic which can be adsorbed on the membrane at equilibrium for a given concentration and $\Gamma_{(t)}$ is the amount of trace organic adsorbed on the membrane surface at time $t$. Thus, the actual solute flux adhering to the membrane surface is:

$$
J=\left[1-\frac{\Gamma_{(t)}}{\Gamma_{e}}\right] C_{0}\left(\frac{D_{(s w)}}{\pi t}\right)^{1 / 2}
$$

In contrast, as discussed earlier, if the pore size of the membrane is sufficiently large, estrone can diffuse, and hence penetrate into the pore of the membrane, which results in increased adsorption. A surface ratio term $\theta$ must be introduced to account for this increase in available adsorptive sites. $\theta$ presents the extent to which adsorption can occur inside the pores of the membranes. In fact, $\theta$ can be used as the ratio of diffusive to convective transport of estrone across the membrane. In the static adsorption process, diffusion is the only driving force; therefore, if adsorption only occurs at the membrane surface the value of $\theta$ will be 1 . Due to surface roughness, the true surface area may be larger, and $\theta$ can be less than 1 . High values of $\theta$ imply that adsorption can occur inside the pore of the membrane. Eq. (6) now becomes:

$$
J=\theta\left[1-\frac{\Gamma_{(t)}}{\Gamma_{e}}\right] C_{0}\left(\frac{D_{(s w)}}{\pi t}\right)^{1 / 2}
$$

The flux of trace organic through the thin film interface at the membrane surface is equal to the change in the mass adsorbed with time:

$$
J=\frac{d \Gamma}{d t}
$$

Eq. (7) and (8) can be solved to yield:

$$
\ln \left(1-\frac{\Gamma_{(t)}}{\Gamma_{e}}\right)=\frac{-2 C_{0} \theta}{\Gamma_{e}}\left(\frac{D_{(s w)}}{\pi}\right)^{1 / 2} t^{1 / 2}
$$

The diffusion coefficient of estrone can be estimated based on its molecular mass as described by Worch (1993) and the Stokes Einstein equation based on an equivalent sphere of the molecules. Since $D_{(\mathrm{sw})}\left(5.4 \times 10^{-10} \mathrm{~m}^{2} / \mathrm{s}\right)$ is an assumed constant, $\theta$ can be determined from the experimental data (see Figure 10). Values of $\theta$ for different membranes are shown in Table 2.

The value of $\theta$ for the $X-20$ membrane is close to 1 which indicates that estrone has not penetrated into the pore of the membrane active layer and the transport of estrone across this layer will be dominated solely by a diffusion process. Since the diffusion process of trace organics in the membrane material is usually much slower than the convective transport of water, estrone retention by the $\mathrm{X}-20$ is high as can be confirmed by our experiment results presented earlier (Nghiem et al., accepted). In contrast, the TFC-SR2, $\mathrm{XN}-40$ and TFC-SR1 membranes have high value of $\theta$ (7.7, 6.8 and 6.3 respectively). This suggests that estrone would readily penetrate into the pores of those membranes and transport of estrone across the membrane will largely depend on convection. These results are confirmed by retention results obtained in cross-flow filtration (Nghiem et al, in preparation), where those membranes showed a very low retention of estrone.

\section{CONCLUSIONS}

This study investigates the adsorptive behaviour of trace contaminant estrone by eight different NF/RO membranes using a variety of experimental designs. The membranes can adsorb trace contaminant estrone, which may result in an initially high retention, and for the loose membranes (such as TFC-S) breakthrough curves were observed when the membrane adsorptive sites are saturated. Tight membranes (RO) such as X-20 show a membrane adsorptive sites are saturated. Tight membranes $(R O)$ such as $X-20$ show a high potential in the removal of trace contaminant estrone, since estrone cannot $p$
into the membrane pores and adsorption can only occur at the membrane surface.

into the membrane pores and adsorption can only occur at the membrane surface.

Although the effect of ionic strength on estrone adsorption by the membrane is negligible, it may be strongly influenced by $\mathrm{pH}$ near the $\mathrm{pKa}$ value of estrone adsorption experiments give a linear adsorption isotherm, higher estrone adsorption during the filtration process with a large pore size membrane (TFC-SR2) suggests that adsorption can also occur inside the membrane. At this stage it is not possible to clearly differentiate between adsorption in the active layer and the support. In the experiments performed in this study, the support layer cannot engage in hydrogen bonding with the molecules and hence adsorption would be expected to be lower.

Depending on the membrane pore size, the transport of trace organics across the membrane layer can be diffusive and/or convective in nature. A modified diffusion model (Jones and O'Melia, 2000) has been adapted to quantify $\theta$, the ratio of diffusive to convective transport of estrone across the membrane. This model may be used as an indication of trace organics retention in NF/RO membranes and to gain further understanding of their retention mechanisms.

\section{ACKNOWLEDGEMENTS}

The Queensland Government and the Australian Research Council are thanked for project funding under the SPIRT scheme. We acknowledge Koch Membrane Systems (San Diego, USA) and Trisep Corporation (Goleta, USA) for providing membrane samples. Thomas Melin and Thomas Wintgens from RWTH Aachen, Germany are thanked for stimulating discussions.

\section{SYMBOLS}

$\begin{array}{lll}\mathrm{C} & = & \text { concentration, } \mathrm{g} / \mathrm{cm}^{3} \\ \mathrm{C}_{0} & = & \text { initial bulk concentration, } \mathrm{ngL}^{-1} \\ \mathrm{C}_{\mathrm{F}} & = & \text { feed concentration, } \mathrm{ngL}^{-1} \\ \mathrm{C}_{\mathrm{pi}} & = & \text { permeate concentration, } \mathrm{ngL}^{-1} \\ \mathrm{C}_{\mathrm{c}} & = & \text { concentrate concentration, } \mathrm{ngL}^{-1} \\ \mathrm{~V}_{\mathrm{F}} & = & \text { feed volume, } \mathrm{L} \\ \mathrm{V}_{\mathrm{pi}} & = & \text { permeate volume, } \mathrm{L} \\ \mathrm{V}_{\mathrm{c}} & = & \text { concentrate volume, } \mathrm{L} \\ \mathrm{D}_{(\mathrm{sw})} & = & \text { diffusion coefficient in water } \mathrm{m}^{2} / \mathrm{s} \\ \Gamma_{\mathrm{e}} & = & \text { mass of material adsorbed per surface area at equilibrium, } \mathrm{ng} / \mathrm{cm}^{2} \\ \Gamma_{(\mathrm{t})} & = & \text { mass of material adsorbed per surface area at time } \mathrm{t}, \mathrm{ng} / \mathrm{cm}^{2}\end{array}$


Nghiem, L.D. ; Schäfer, A.I. (2002) Adsorption and Transport of Trace Contaminant Estrone in NF/RO Membranes, Environmental Engineering Science (invited special issue paper) $19,6,441-451$. doi:10.1089/109287502320963427.

$$
\begin{array}{ll}
= & \text { mass flux } \mathrm{m}^{3} / \mathrm{m}^{2} / \mathrm{s} \\
= & \text { distance, } \mathrm{m} \\
= & \text { diffusive to convective ratio, }- \\
= & \text { time, } \mathrm{s}
\end{array}
$$

\section{REFERENCES}

BAIER, J.H., LYKINS JR, B.W., FRONK, C.A., KRAMER, S.J. (1987) Using Reverse Osmosis to Remove Agricultural Chemicals From Groundwater. J. AWWA. August, $\mathrm{p}$ $55-60$.

BERG, P., HAGMEYER, G., AND GIMBEL, R. (1997) Removal of pesticides and other micropollutants by nanofiltration. Desalination. 113, 205-208.

CHIAN, E.S.K., BRUCE, W.N., FANG, H.H.P. (1975) Removal of pesticides by reverse osmosis. Environmental Science \& Technology. 1, 52-59.

DO, D.D. (2001). Adsorption Analysis: Equilibria and Kinetics. London: Imperial College Press.

DURANCEAU, S.J., TAYLOR, J.S., MULFORD, L.A. (1992) SOC removal in a membrane softening process. J. AWWA. Jan, 68-78.

EUROPEAN COMMISSION (1996). Proceedings of the European Workshop on the Impact of Endocrine Disrupters on Muman Health and Wildlife. Weybridge, UK

FANG, H.H.P AND CHIAN, E.S.K (1976) Reverse Osmosis Separation of Polar Organic Compounds in Aqueous Solution. Environmental Science \& Technology. 10, 364-375.

HARRIES J.E, SHEAHAN D.A, JOBLING S,MATTHIESSEN P, NEALL P, SUMPTER J.P TYLOR T, ZAMAN N (1997) Estrogenic activities at five UK rivers detected by measurement of vitellogenesis in caged male trout. Environmental Toxicology and Chemistry. 16, 534-542.

JOBLING S, NOLAN M, TYLER C.R, BRIGHTY G, J.P Sumpter (1998) Widespread sexual disruption in wild fish. Environmental Science and Technology. 32, 2498-2506.

JOHNSON, A.C AND SUMPTER, J.P. (2001) Removal of Endocrine-Disrupting Chemicals in activated sludge treatment works. Environmental Science \& Technology. 35, 4697-4703.

JONES, K.L., AND O'MELIA, C.R., (2000) Protein and humic acid adsorption onto hydrophilic membrane surfaces: effects of $\mathrm{pH}$ and ionic strength. J. Membrane Science. 165, 31-46.

KISO, Y., NISHIMURA, Y., KITAO, T., NISHIMURA, K. (2000). Rejection properties of non-phenylic pesticides with nanofiltration membranes. Journal of Membrane Science, 171, 229-237.

KISO, Y., KON, T., KITAO, T., NISHIMURA, K. (2001) Rejection properties of alkyl phthalates with nanofiltration membranes. Journal of Membrane Science, 182, 205214.

MERCK, B.S. (1996). Merck index. $12^{\text {th }}$ Ed. Merck \& Co., Inc, New Jersey.

NGHIEM, D.L., SCHÄFER, A.I., WAITE, T.D. (2002) Adsorptive interactions between membranes and trace contaminants. Desalination. Accepted Feb 2002.

NGHIEM, D.L., SCHÄFER, A.I., MANIS, A., SOLDENHOFF, K. Crossflow filtration of estrone and comparison of retention with stirred cell experiments. Journal of Membrane Science. In preparation.

PURDOM C.E, HARDIMAN P.A, BYE V.J, ENO N.C, TYLER C.R, SUMPTER J.P (1994) Estrogenic effects of effluents from sewage treatment works. Chemistry and Ecology. 8, 275-285.
PIVA, F., MARTINI, L. (1998) Neurotransmitters and the control of hypophyseal gonadal functions: possible implications of endocrine disruptors. Pure Apply Chemistry. 70, 1647-1656.

REINHARD, M., GOODMAN, N.L., MCCARLY, P.L., ARGO, D.G (1986) Removing Trace Organics by Reverse Osmosis using Cellulose Acetate and Polyamide Membranes. $J$. AWWA. April. 163-174.

RODGERS-GRAY, T.P., JOBLING, S., KELLY, C., MORRIS, S., BRIGHTY, G., WALDOCK, M.J., SUMPTER, J.P., TYLER, C.R., (2001) Exposure of juvenile roach (Rutilus rutilus) to treated sewage effluent induces dose-dependent and persistent disruption in gonadal duct development. Environmental Science \& Technology. 35, 462-470.

SCHÄFER, A.I., NGHIEM, D.L., WAITE, T.D. (2001). Removal of natural hormone estrone from Water and Wastewater using Nanofiltration and Reverse Osmosis. Environmental Science \& Technology (submitted).

SCHÄFER, A.I., NGHIEM, D.L., WAITE, T.D. (2001). Removal of natural hormone estrone from secondary effluent and surface waters using membranes. In G. Oron and A. Bick, Eds., Proceedings of the International Conference on Membrane Technology for Wastewater Reclaimation and Reuse. Tel-Aviv, pp 259-566.

TERNES, T.A., STUMPF, M., MUELLER, J., HABERER, K., WILKEN, R.-D., SERVOS, M. (1999a). Behavior and occurrence of estrogens in municipal sewage treatment plants - I. Investigations in Germany, Canada and Brazil. The Science of the Total Environment, 225, 81-90.

THORPE, K.L., HUTCHINSON, T.H., HETHERIDGE, M.J., SCHOLZE, M., STUMPTER, J.P., TYLER, C.R., (2001) Assessing the biological potency of binary mixtures of environmental estrogens using vittellogenin induction in juvenile rainbow trout (Oncorhynchusmykiss). Environmental Science \& Technology. 35, 2476-2481.

TURAN, A (1995) Excretion of Natural and Synthetic Estrogens and their Metabolites: Occurrence and Behaviour in water. Workshop report, German Environmental Agency. Berlin

WILLIAMS, M.E., HESTEKIN, J.A., SMOTHER, C.N., and BHATTACHARYYA, D., (1999) Separation of Organic Pollutants by Reverse Osmosis and Nanofiltration Membranes: Mathematical Models and Experimental Verification. Industrial Engineering Chemistry. 38, 3683-3695.

WIESNER, M.R and BUCKLEY, C.A (1996). Principles of rejection in pressure driven membrane processes. In J. Mallevialle, P.E. Odendaal, M.R. Wiesner, Eds., Water Treatment Membrane Processes. New York, McGraw Hill., p 5.1.

WORCH, E. (1993) Eine neue Gleichung zur Berechnung von Diffusionskoeffizienten gelöster Stoffe. Vom Wasser, 81, 289-297.

Corresponding author:

Dr Andrea Schäfer

Civil and Environmental Engineering

The University of New South Wales

SYDNEY NSW 2052

AUSTRALIA

ph ++61293854470

fax ++61293856139

email: A.Schaefer@unsw.edu.au 
Nghiem, L.D. ; Schäfer, A.I. (2002) Adsorption and Transport of Trace Contaminant Estrone in NF/RO Membranes, Environmental Engineering Science (invited special issue paper) 19, 6, 441-451. doi:10.1089/109287502320963427.

\section{TABLES}

Table 1 Membrane Types and Pure Water Fluxes at 5 bar

\begin{tabular}{lccc}
\hline $\begin{array}{c}\text { Membrane } \\
\text { Type }\end{array}$ & $\begin{array}{c}\text { Average Pure } \\
\text { Water Flux } \\
{\left[\mathbf{L m}^{-2} \mathbf{h}^{-1}\right]}\end{array}$ & $\begin{array}{c}\text { Membrane } \\
\text { Resistance } \\
{\left[\mathbf{m}^{-1}\right]}\end{array}$ & $\begin{array}{c}\text { Membrane } \\
\text { Material }\end{array}$ \\
\hline TFC-ULP & $33.4 \pm 6.7$ & $5.4 \cdot 10^{13}$ & Polyamide on \\
TFC-S & $55.0 \pm 7.3$ & $3.3 \cdot 10^{13}$ & $\begin{array}{c}\text { Polysulphone } \\
\text { support }\end{array}$ \\
TFC-SR1 & $52.6 \pm 9.4$ & $3.4 \cdot 10^{13}$ & \\
TFC-SR2 & $77.0 \pm 25.2$ & $2.3 \cdot 10^{13}$ & $9.4 \cdot 10^{13}$ \\
\hline X-20 & $19.2 \pm 2.4$ & $7.0 \cdot 10^{13}$ & Polyamide-urea \\
ACM-4 & $25.8 \pm 8.0$ & $4.2 \cdot 10^{13}$ & Composite \\
XN-40 & $42.5 \pm 0.8$ & $6.9 \cdot 10^{13}$ & \\
TS-80 & $26.0 \pm 12.5$ & & \\
\hline * Average values are derived from all experiments and variations are averaged
\end{tabular}

Table 2: Diffusive to convective ratio $(\theta)$ and equilibrium concentration for different membranes using the modified diffusion model.

\begin{tabular}{|c|c|c|}
\hline Membrane & $\Gamma \mathrm{e}\left(\mathrm{ngcm}^{-2}\right)$ & $\theta$ \\
\hline $\mathrm{XN}-40$ & 0.0897 & 6.8 \\
\hline TS-80 & 0.0738 & 2.4 \\
\hline ACM-4 & 0.0702 & 2.0 \\
\hline$X-20$ & 0.0519 & 1.2 \\
\hline TFC-SR1 & 0.0910 & 6.3 \\
\hline TFC-SR2 & 0.0962 & 7.7 \\
\hline TFC-S & 0.0765 & 3.3 \\
\hline TFC-ULP & 0.0853 & 4.2 \\
\hline
\end{tabular}

\section{FIGURES}

Figure 1: Schematic of possible hydrogen bonding between the estrone molecule and the membrane functional groups

Figure 2: Permeate concentration of estrone as a function of permeate volume $(1 \mathrm{mM}$ $\mathrm{NaHCO}_{3}, 20 \mathrm{mM} \mathrm{NaCl}$, and $\mathrm{pH}$ 8.0)

Figure 3: Adsorption of estrone as a function of $\mathrm{pH}$ in TFC-SR2 membrane after filtration of $120 \mathrm{~mL}(1 \mathrm{mM} \mathrm{NaHCO} 3,20 \mathrm{mM} \mathrm{NaCl})$.

Figure 4: Adsorption of estrone as a function of $\mathrm{NaCl}$ after filtration of $120 \mathrm{~mL}$ (TFC-SR2 membrane, $1 \mathrm{mM} \mathrm{NaHCO}_{3}$ and $\mathrm{pH} 8.0$ ).

Figure 5: Adsorption as a function of feed concentration in filtration experiment after filtration of $120 \mathrm{~mL}\left(1 \mathrm{mM} \mathrm{NaHCO}_{3}, 20 \mathrm{mM} \mathrm{NaCl}\right.$, and $\mathrm{pH}$ 8.0).

Figure 6: Adsorption isotherm of TFC-SR2 and X-20 (static adsorption experiment, $1 \mathrm{mM}$ $\mathrm{NaHCO}_{3}, 20 \mathrm{mM} \mathrm{NaCl}$, and pH 8.0).

Figure 7: Adsorption kinetics in static experiments $\left(1 \mathrm{mM} \mathrm{NaHCO}_{3}, 20 \mathrm{mM} \mathrm{NaCl}, 100\right.$ $\mathrm{ng} / \mathrm{L}$ estrone and $\mathrm{pH} 8.0)$.

Figure 8: Desorption kinetics in static experiments $\left(1 \mathrm{mM} \mathrm{NaHCO}_{3}, 20 \mathrm{mM} \mathrm{NaCl}, 100\right.$ $\mathrm{ng} / \mathrm{L}$ estrone and $\mathrm{pH} 8.0)$

Figure 9: Transport of trace organics across "ideal" NF (convective) and RO (diffusive) membranes.

Figure 10: Relationships between the logarithm $\ln [1-\Gamma(t) / \Gamma e]$ and the square root of time, $\mathrm{t}^{1 / 2}\left(1 \mathrm{mM} \mathrm{NaHCO}_{3}, 20 \mathrm{mM} \mathrm{NaCl}, 100 \mathrm{ng} / \mathrm{L}\right.$ estrone and $\mathrm{pH}$ 8.0) 
Nghiem, L.D. ; Schäfer, A.I. (2002) Adsorption and Transport of Trace Contaminant Estrone in NF/RO Membranes, Environmental Engineering Science (invited special issue paper) 19,6 , $441-451$. doi:10.1089/109287502320963427.

Figure 1
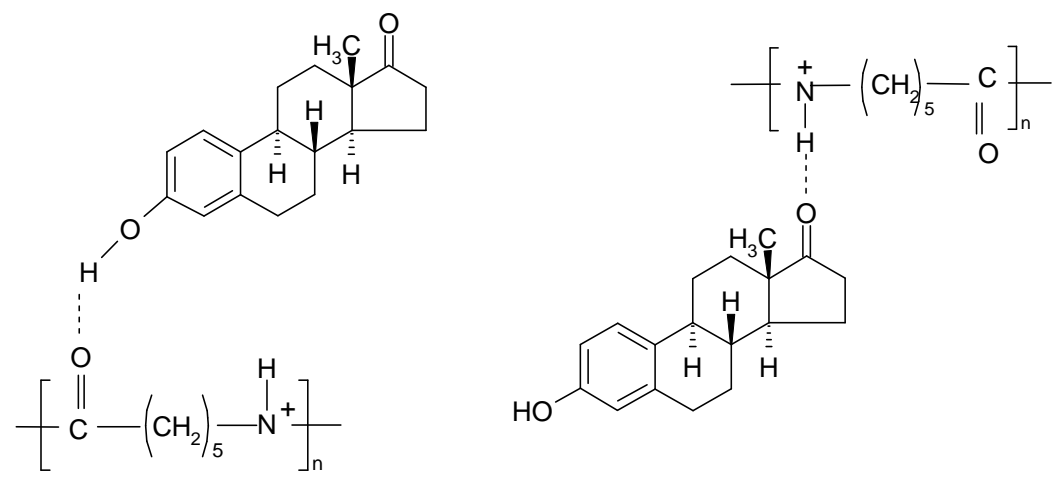

\section{Figure 2}

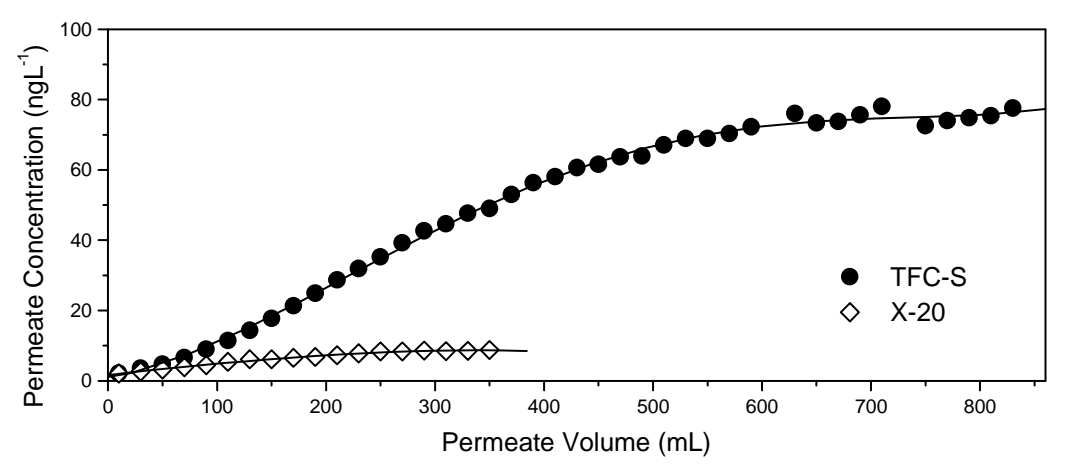

\section{Figure 3}

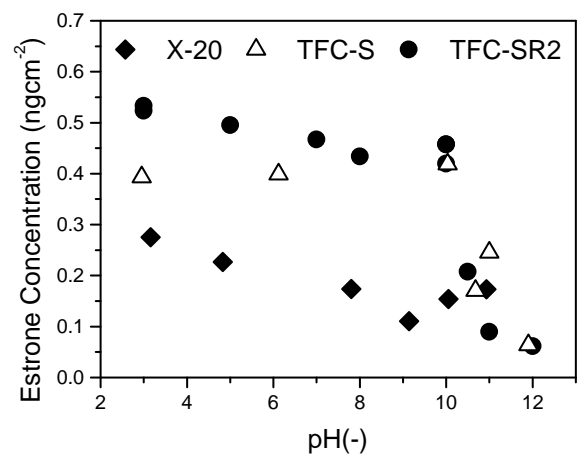

Figure 4

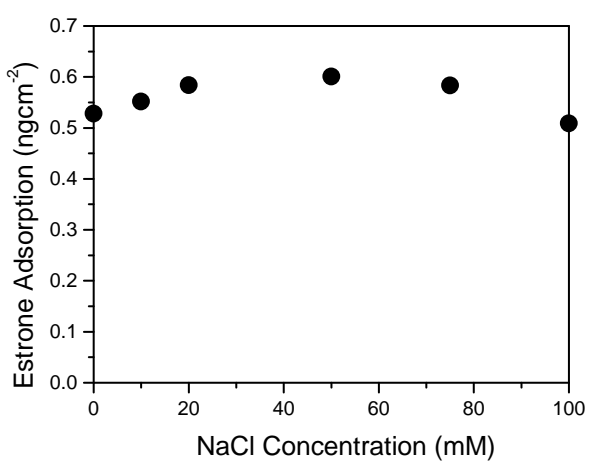


Nghiem, L.D. ; Schäfer, A.I. (2002) Adsorption and Transport of Trace Contaminant Estrone in NF/RO Membranes, Environmental Engineering Science (invited special issue paper) 19,6 , $441-451$. doi:10.1089/109287502320963427.

Figure 5

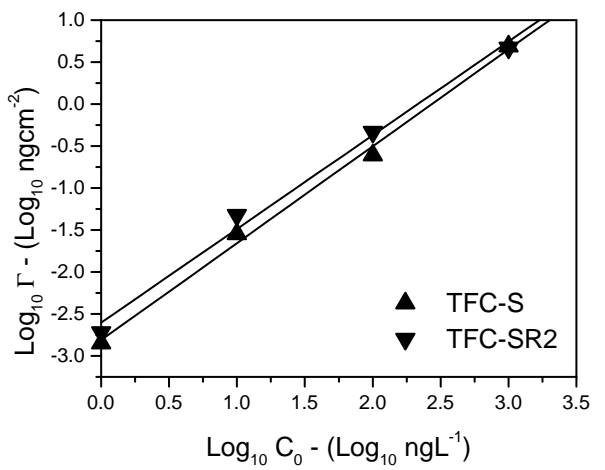

Figure 6

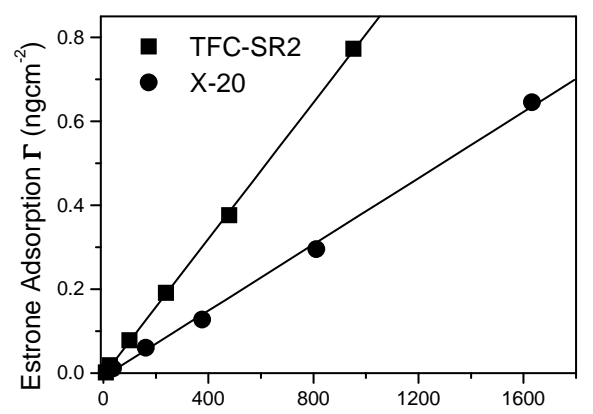

Estrone Concentration $\left(\mathrm{ngL}^{-1}\right)$
Figure 7
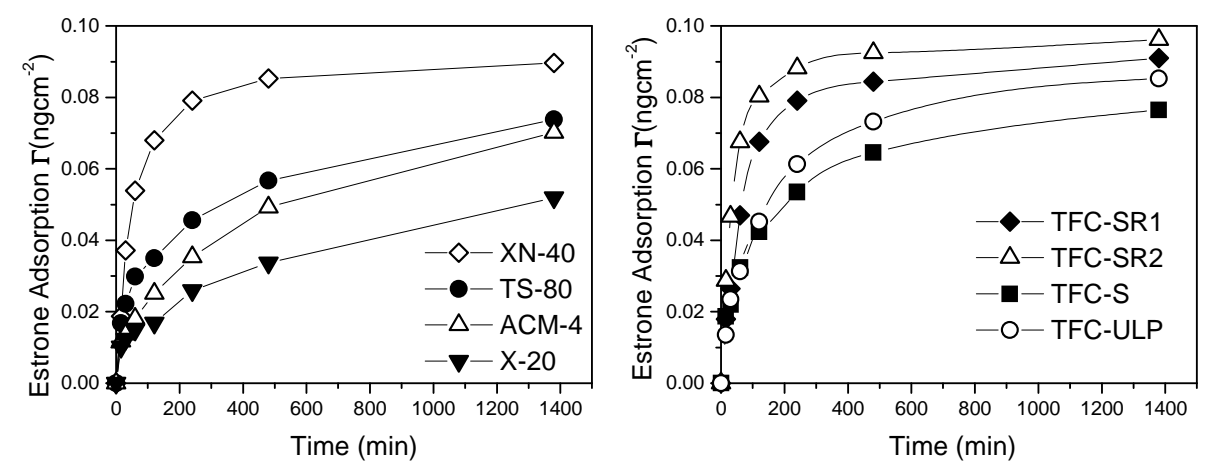

Figure 8
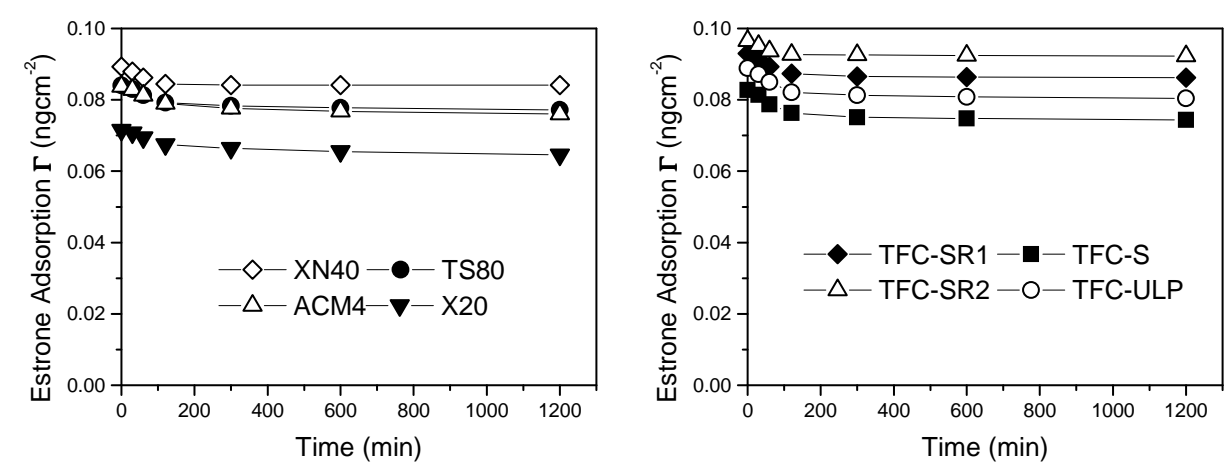
Nghiem, L.D. ; Schäfer, A.I. (2002) Adsorption and Transport of Trace Contaminant Estrone in NF/RO Membranes, Environmental Engineering Science (invited special issue paper) 19, 6, 441-451. doi:10.1089/109287502320963427.

Figure 9

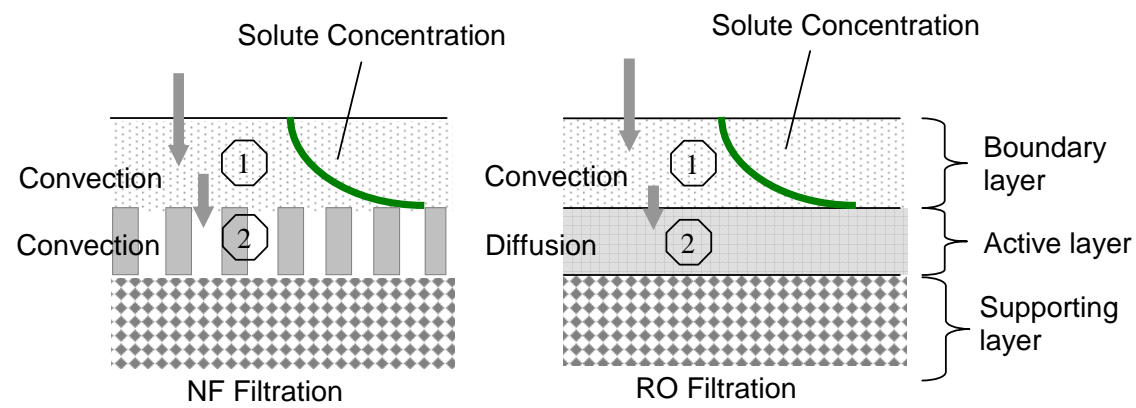

Figure 10
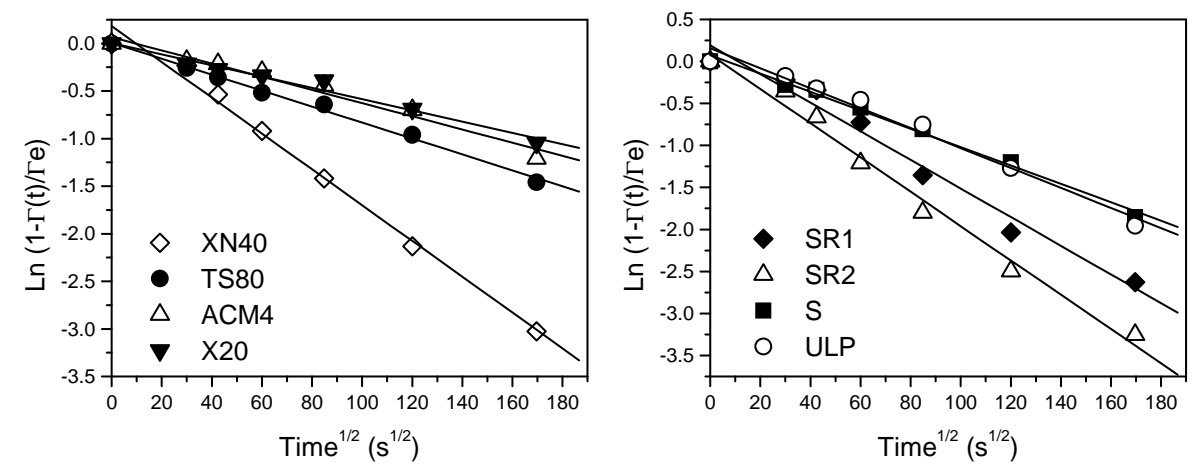